\title{
Hajuhaitan vähentäminen maatalouden suurissa eläintuotantoyksiköissä
}

\author{
Mona Arnold ${ }^{1)}$ ja Maarit Puumala ${ }^{2)}$ \\ ${ }^{1)}$ VTT Prosessit PL 160202044 VTT, mona.arnold@vtt.fi \\ ${ }^{2)}$ MTT Maatalousteknologian tutkimus (Vakola), Vakolantie 5503400 Vihti, maarit.puumala@mtt.fi
}

\section{Johdanto}

Suomen kotieläintuotannon yksikkökoot ovat merkittävästi kasvamassa. Kotieläinten tehokasvatuksessa toiminnan ympäristövaikutukset korostuvat. Erityisen konkreettinen ja ajankohtainen ympäristöhaitta on haju. Suuria tuotantoyksiköitä ja asuintaloja rakennetaan lähelle toisiaan, mikä yhdistettynä maaseudun väestöpohjan muuttumiseen korostaa entisestään hajuhaittaa. Hajuhaitta vähentää maaseudun vetovoimaa ja voi pahimmillaan haitata maaseudun monitoimimahdollisuuksia, kuten matkailua.

Kotieläinrakennusten ympäristöluvista valitetaan yhä useammin. Tuotantoyksiköiden hajuhaittojen hallinnasta ei toisaalta vielä ole yhtenäistä käytäntöä. Tarve tutkittuun tietoon perustuvalle ohjauskäytännölle ja kotieläintuotannon hajua vähentäville tekniikoille on näin ollen suuri.

Ympäristöministeriössä on valmistunut ehdotus kotieläinsuojien ympäristölupamenettelyjen selkeyttämiseksi. Ehdotukseen sisältyy suositus kotieläinrakennusten sijoittumisesta hajuhaitan ehkäisemiseksi. Suositus perustuu kotieläinrakennuksen eläinmäärään ja kyseisen eläintyypin lannan fosforisisältöön eikä tutkittuun tietoon hajun muodostumisesta ja leviämisestä.

Suomessa ei ole ajankohtaisuudestaan huolimatta merkittävästi tutkittu kotieläintuotannon aiheuttamia hajupäästöjä tai niiden vaikutusta lähiasujamistoon. Vähäpäästöisen tuotantotekniikan T\&K on tähän asti keskittynyt lähes yksinomaan maaperään ja vesistöihin suuntautuviin sekä ammoniakkipäästöihin. Hajua vähentäviä toimia ole tutkittu.

Kaksi vuotta kestävän hankkeen tavoitteena on selvittää kotieläintuotannosta syntyvän hajun määrä sekä kehittää keinoja, joilla hajuhaittoja voidaan vähentää ja ehkäistä. Lisäksi etsitään tapoja, joilla kotieläintuotanto voidaan kytkeä yhteen asutuksen ja virkistyksen kanssa.

Ensimmäisessä osassa selvitetään esimerkkitapauksin kotieläinyksiköiden aiheuttamaa hajukuormaa ja hajun aiheuttamaa viihtyisyyshaittaa. Tässä ensimmäisessä vaiheessa on keskitytty esimerkkitilojen hajupäästöjen mittauksiin. Esimerkkitapausten avulla määritetään hajupäästön riippuvuutta yksikön eläinmäärästä "hajupäästö/eläinpaikka", jonka perusteella voidaan jatkossa arvioida eri kokoisten kotieläinyksiköiden hajuvaikutusta ilman mittavia hajumittauksia.

\section{Aineisto ja menetelmät}

Mittausten esimerkkilaitokset ovat sikaloita (eri kokoluokan yhdistelmä- ja emakkosikalat) ja broilerkasvattamoita (kaksi eri kuivikevaihtoehtoa) (taulukko 1). Esimerkkitapaukset pyrittiin valitsemaan siten, että ne edustaisivat mahdollisimman hyvin nykyisiä tuotantomenetelmiä.

Taulukko 1. Tutkimuksen esimerkkilaitokset

\begin{tabular}{|l|l|l|l|l|}
\hline & Sikalat & & Broilertilat & \\
\hline Eläinpaikkoja & 586 lihasikaa + 50 emakkoa & 850 emakkoa & 60000 & 60000 \\
\hline Osastoja & 5 & 27 & 6 & 2 \\
\hline tuotanto & jatkuva & jatkuva & erä & erä \\
\hline Ilmanpoisto & katolta & katolta/seinästä & katolta & katolta \\
\hline Pohjat & täysritilä/osaritilä & täysritilä/osaritilä & turve & kutteri \\
\hline Rehu/ruokinta & liemi/kuiva & liemi/kuiva & kuiva & kuiva \\
\hline Lantajärjestelmä & liete (lietesäiliössä kate) & liete & kuiva & Kuiva \\
\hline
\end{tabular}

Mittauskampanjoissa määritettiin tuotantorakennuksen sisäiset olosuhteet, poistoilman hajupitoisuus ja tilavuusvirta. Olosuhdemittauksiin sisältyi eläinsuojan eläinmäärä mittaushetkellä, eläintiheys, valittujen osastojen ammoniakkipitoisuus, kosteus ja lämpötila. Myös ilmanvaihdon tasaisuutta mitattiin. Poistoilman määrä määritettiin kuumalanka-anemometrilla. Hajupitoisuus mitattiin olfaktometrisin menetelmin SFSEN-standarin periaatteiden mukaisesti [SFS-EN ,2003].

Haiseva ilma sisältää yleensä hyvin monia eri epäpuhtauksia, joiden pitoisuudet ovat erittäin pieniä ja vaikeita mitata, eikä eri yhdisteiden vaikutus kokonaishajuun ole tiedossa. Hajupitoisuuden mittana käytetään tällöin hajuyksikköä kuutiometriä kohti (hy $/ \mathrm{m}^{3}$ tai engl. ou/ $\mathrm{m}^{3}$, odour unit $\left./ \mathrm{m}^{3}\right)$, joka kertoo 
suoraan, montako kertaa haiseva ilma on laimennettava, jotta se tulisi hajuttomaksi. Kaasun hajupitoisuus määritetään laboratoriossa olfaktometrilla useammasta koehenkilöstä koostuvan hajupaneelin avulla.

Mittaukset aloitettiin kesällä 2003 ja ne jatkuvat vielä vuonna 2004. Esimerkkisikaloiden hajupäästöt on mitattu molemmat kahdessa mittauskampanjassa kesällä ja syksyllä. Tuloksia on tarkasteltu kokonaispäästönä sekä eläinosastoittain, jolloin on saatu alustava arvio eri eläintyyppien (emakko, lihasika, vieroitettu porsas) eläinkohtaisesta hajupäästöstä ja olosuhteiden vaikutuksesta hajupäästöön.

Broilertilojen hajupäästöt on mitattu yhteensä viidessä mittauskampanjassa kesällä ja syksyllä. Mittaukset kohdistuivat sekä lintuerän kasvatuksen alku- että loppuvaiheeseen. Lintujen paino nousee noin 37 päivän kasvatuksen aikana noin 50 grammasta $1,7 \mathrm{~kg}: \mathrm{n}$. Samanaikaisesti rakennuksen sisälämpötila lasketaan noin $31^{\circ} \mathrm{C}$ :sta $21^{\circ} \mathrm{C}$ :seen.

\section{Tulokset ja tulosten tarkastelu}

Yhteenveto päästömittaustuloksista on taulukossa 1.

Taulukko 1. Esimerkkitilojen päästöt. Kesän ja syksyn 2003 mittaustulokset.

\begin{tabular}{|l|l|l|}
\hline \multirow{2}{*}{} & \multicolumn{2}{|l|}{ Kokonaishajupäästö, milj. h.y./h*) } \\
\cline { 2 - 3 } & Kesän mittaukset & Syksyn mittaukset \\
\hline Emakkosikala & $\begin{array}{l}743 \text { milj. (rakennus) } \\
736 \text { milj. (lietesäiliöt) }\end{array}$ & 315 milj (rakennus) \\
\hline $\begin{array}{l}\text { Yhdistelmäsikala } \\
586 \text { lihasikaa, 50 emakkoa }\end{array}$ & $\begin{array}{l}118,5 \text { milj. (rakennukset) } \\
23,5 \text { milj (lietesäiliö) }\end{array}$ & $\begin{array}{l}77,5 \text { milj. (rakennukset) } \\
\text { lietesäiliötä ei mitattu }\end{array}$ \\
\hline Broilertila 60000 lintua & alkuvaihe 43 milj. & loppuvaihe 277 milj. \\
\hline Broilertila 60000 lintua & alkuvaihe 5,1 milj. & loppuvaihe 133 milj. h \\
\hline
\end{tabular}

*)hajuyksikköä tunnissa

Esimerkkilaitosten mittaukset osoittavat selvän eron kesän ja syksyn tulosten välillä. Korkeampi ulkolämpötila johtaa suurempiin päästöihin. Samanlaisia tuloksia on esitetty myös muualla. Ulkomaiset vastaavat tutkimukset ovat osoittaneet, että tulosten vaihtelu on tällaisille hajumittauksille tyypillistä. Esim. belgialaisessa tutkimuksessa sikalaosaston hajupäästö vaihteli välillä 5000 hy/s (helmi-huhtikuu) ja 30000 - 55000 hy/s (kesä-elokuu) [Hendriks et al. 2001]. Päästön suuruuteen vaikuttaa lisäksi eläinmäärä mitatussa osastossa, eläinten aktiviteetti, ruokinnan ajoitus, ilmanvaihdon tehokkuus, karsinan siisteys jne., joten suuret vaihtelut ovat mittaukselle yleisesti tyypillisiä.

Taulukoissa 2-5 on verrattu syksyn ja kesän mittaustuloksia hajupäästöjen ja rakennusten olosuhteiden osalta. Hajupäästö on esitetty sekä eläinmassaa kohti. 
Taulukko 2. Emakkosikalan osastojen kesän ja syksyn 2003 mittaustulokset (ei kattava)

\begin{tabular}{|c|c|c|c|c|c|c|c|c|c|c|}
\hline & \multicolumn{5}{|c|}{ Kesä 2003} & \multicolumn{5}{|c|}{ Syksy 2003} \\
\hline & $\begin{array}{l}\text { Lämpö- } \\
\text { tila } \\
{ }^{\circ} \mathrm{C}\end{array}$ & $\begin{array}{l}\text { Kosteus } \\
\%\end{array}$ & $\begin{array}{l}\text { Ammo- } \\
\text { niakki } \\
\mathrm{ppm} / \mathrm{h}\end{array}$ & $\begin{array}{l}\text { Ilman- } \\
\text { vaihto, } \\
\mathrm{m}^{3} / \mathrm{h} \mathrm{kg} \\
\text { eläin- } \\
\text { massaa }\end{array}$ & $\begin{array}{l}\text { Haju- } \\
\text { päästö, } \\
\text { hy/s.500 } \\
\text { kg eläin- } \\
\text { massaa }\end{array}$ & $\begin{array}{l}\text { Lämpö- } \\
\text { tila } \\
{ }^{\circ} \mathrm{C}\end{array}$ & $\begin{array}{l}\text { Kosteus } \\
\%\end{array}$ & $\begin{array}{l}\text { Ammo- } \\
\text { niakki } \\
\mathrm{ppm} / \mathrm{h}\end{array}$ & $\begin{array}{l}\text { Ilman- } \\
\text { vaihto, } \\
\mathrm{m}^{3} / \mathrm{h} \mathrm{kg} \\
\text { eläin- } \\
\text { massaa }\end{array}$ & $\begin{array}{l}\text { Haju- } \\
\text { päästö, } \\
\text { hy/s·500 } \\
\text { kg eläin- } \\
\text { massaa }\end{array}$ \\
\hline Joutilaat & 21 & 65 & 15 & 0,5 & 70 & 17 & 61,5 & 48,3 & $0,07 *$ & 19 \\
\hline Ensikot & 25 & 51 & 21 & 0,9 & 1548 & & & & 0,8 & 362 \\
\hline Siemennys & 22 & 56 & 21 & 0,6 & 107 & 16 & 55,1 & 18,7 & 0,6 & 125 \\
\hline Porsitus & & & & 0,9 & 178 & 23 & 41,1 & 13,5 & 0,2 & 67 \\
\hline Vierotus 1 & 23 & 55 & 3,5 & 6,9 & 1340 & & & & & \\
\hline Vierotus 3 & & & & 1,7 & 358 & 20 & 53,0 & 8,3 & 2,3 & 134 \\
\hline Vierotus 27 & & & & 2,2 & 192 & 35 & 46,2 & 7,3 & 0,25 & 21 \\
\hline Karjut & & & & 1,4 & 513 & 18 & 49,5 & 13,6 & 0,94 & 352 \\
\hline
\end{tabular}

* ikkunoita auki

Yhdistelmäsikalan tulokset vaihtelivat laajasti kaikkien mitattujen parametrien osalta eri osastojen välillä. Ensikoiden hajupäästö eläinmassaa kohti laskettuna oli erityisen korkea, samoin vieroitusosasto 1:en. Ensikko-osastossa poistoilma johdettiin seinästä ulos, osittain lietekuilun kautta. Muissa osastoissa ilma vaihtui yläpoistona.

Vieroitusosastojen eläinmassakohtainen hajupäästö vaihteli eläinten iän ja keskimassan mukaan. Nuorempien vieroitettujen porsaitten (keskim. $7 \mathrm{~kg}$ ) massakohtainen hajupäästö on huomattavasti korkeampi kuin isoimpien (keskipaino $20 \mathrm{~kg}$ ). Eläinmäärän mukaan laskettuna hajupäästö oli näissä osastoissa samalla tasolla.

Taulukko 3. Yhdistelmäsikalan kesän ja syksyn 2003 mittaustulokset

\begin{tabular}{|c|c|c|c|c|c|c|c|c|c|c|}
\hline & \multicolumn{5}{|c|}{ Kesä 2003} & \multicolumn{5}{|c|}{ Syksy 2003} \\
\hline & $\begin{array}{l}\text { Lämpö- } \\
\text { tila } \\
{ }^{\circ} \mathrm{C}\end{array}$ & Kosteus & $\begin{array}{l}\text { Ammo- } \\
\text { niakki } \\
\mathrm{ppm} / \mathrm{h}\end{array}$ & $\begin{array}{l}\text { Ilman- } \\
\text { vaihto, } \\
\mathrm{m}^{3} / \mathrm{h} \mathrm{kg} \\
\text { eläin- } \\
\text { massaa }\end{array}$ & $\begin{array}{l}\text { Haju- } \\
\text { päästö, } \\
\text { hy/s·500 } \\
\text { kg eläin- } \\
\text { massaa }\end{array}$ & $\begin{array}{l}\text { Lämpö- } \\
\text { tila } \\
{ }^{\circ} \mathrm{C}\end{array}$ & Kosteus & $\begin{array}{l}\text { Ammo- } \\
\text { niakki } \\
\mathrm{ppm} / \mathrm{h}\end{array}$ & $\begin{array}{l}\text { Ilman- } \\
\text { vaihto, } \\
\mathrm{m}^{3} / \mathrm{h} \mathrm{kg} \\
\text { eläin- } \\
\text { massaa }\end{array}$ & $\begin{array}{l}\text { Haju- } \\
\text { päästö, } \\
\text { hy/s·500 } \\
\text { kg eläin- } \\
\text { massaa }\end{array}$ \\
\hline Lihasiat (eı & 18,4 & 53,8 & 4,3 & 2,1 & 362 & 16,5 & 67,2 & 1,3 & 5,0 & 410 \\
\hline Lihasiat (kasvatus) & 19,9 & 57,9 & 17,9 & 0,6 & 434 & 21,6 & 68,3 & 10,4 & 0,4 & 115 \\
\hline Lihasiat (lastaus) & 20,6 & 61,3 & 13,4 & 0,9 & 467 & 21,2 & 66,2 & 10,4 & 1,0 & 318 \\
\hline Porsitus & 20,6 & 57,9 & 22,3 & 2,2 & 1550 & 23,9 & 59,5 & 11,4 & 1,1 & 303 \\
\hline Vierotus & 23,3 & 54,5 & 40,9 & 0,1 & 55 & 23,6 & 61,2 & 37,4 & 1,2 & 307 \\
\hline
\end{tabular}

Lihasikalasta mitatut hajupäästöt ovat keskimäärin korkeammat kuin kirjallisuudessa esitetyt arvot, mutta kuitenkin samaa suuruusluokkaa. Guingandin yhteenvedon (2003) mukaan lihasian hajupäästöt vaihtelevat eri tutkimuksissa välillä $20-500 \mathrm{hy} / \mathrm{s} / 500 \mathrm{~kg}$. Suuri vaihteluväli kuvastaa mittausolosuhteiden, erityisesti ilmanvaihdon merkitystä päästöjen suuruuteen.

Taulukko 4. Tulokset turvepohjaiselta broilerikasvattamolta

\begin{tabular}{|l|c|cc|}
\hline & Kesä & Kesä & \multicolumn{2}{c|}{ Syksy } \\
& alkuvaihe & \multicolumn{2}{|c}{ loppuvaihe } \\
Ilmanvaihto/eläin $\mathrm{m}^{3} / \mathrm{h} \mathrm{kg}$ eläinmmassaa & 0,03 & 4,1 & 4,0 \\
Hajupäästö/eläin hy/s lintu & 0,02 & 1,1 & 0,6 \\
Ammoniakki, ppm/h & & $35-37$ & $8-13$ \\
Kosteus, \% & & $55-58$ & $58-60$ \\
Lämpötila, ${ }^{\circ} \mathrm{C}$ & & 23 & 23 \\
\hline
\end{tabular}


Taulukko 5. Tulokset kutterinlastupohjaiselta broilerikasvattamolta

\begin{tabular}{|l|c|c|}
\hline & Kesä & Syksy \\
Ilmanvaihto/eläin, m³/h kg eläinmassaa & 0,15 & 8,4 \\
loppukasvatus \\
Hajupäästö/eläin, hy/s lintu & 0,2 & 1,3 \\
Ammoniakki, ppm/h & 2,1 & 34 \\
Kosteus, \% & 61 & 60 \\
Lämpötila, ${ }^{\circ} \mathrm{C}$ & 31 & 21 \\
\hline
\end{tabular}

Broilerikasvattamoista mitatut hajupäästöt olivat alkuvaiheessa merkittävästi pienempiä kuin loppukasvatuksessa. Lisäksi turvepohjalta hajupäästöt olivat kaikkiaan pienempiä.

\section{Johtopäätökset ja jatkosuunnitelmat}

Kokonaishajupäästöarvioita tullaan jatkossa käyttämään hajun leviämisen arviointiin. Tehtyjä päästömittauksia täydennetään edelleen talvella tehtävillä mittauksilla. Jatkossa käydään myös tarkemmin läpi eri osastojen ilmanvaihtoratkaisuja, lannanpoistojärjestelmiä jne., jolloin voidaan arvioida, miten kyseiset tekniset ratkaisut vaikuttavat päästöihin.

Esimerkkilaitosten päästöistä aiheutuvat hajupitoisuudet ympäristössä mallinnetaan mittaustulosten perusteella. Leviämislaskelmien ja viihtyisyyshaittatutkimusten tulokset antavat yhdessä tietoa siitä, miten häiritseväksi haju koetaan eri etäisyyksillä tuotantolaitoksista ja miten usein hajua esiintyy ulkoilmassa kyseisessä kohteessa. Tulosten perusteella arvioidaan esimerkkilaitosten hajupäästön annos-vastesuhdetta ja suositeltavaa vähimmäisetäisyyttä. Erityisesti saatuja tuloksia tarkastellaan ympäristöministeriön ohjeellista vähimmäisetäisyyskäyrästöön ja muissa maissa tehtyihin hajututkimuksiin ja johtopäätöksiin [Arnold, 2002] nähden.

\section{Kirjallisuus}

Arnold, M. 2002. Eläinsuojien hajuhaitat - ohjeistusmallit, arviointi ja vähentäminen sekä käytäntö eri maissa. Susies - Loppuraportti 15.3.2002. Alueelliset ympäristöjulkaisut no 264.

Guingand, N. 2003. Air quality and reduction of slatted floor in growing -finishing pig units. International Symposium on Gaseous and Odour Emissions from Animal Production Facilities. Horsens 1-4 June 2003. Denmark.

Hendriks, J., Andries, A., Saevels, P., Leribaux, S., Vranken, E., Vinckier, C., Berckmans, D., De Bruyn, G., Baron, M. \& Van Langenhove, H. 2001. Ontwikkeling van een eenvoudige procedure voor debepaling van geuren ammoniakemissies van agrarische constructies ten behoeve van een aangepaste milieureglementering in Vlaanderen Deel 2: Meetprocedure voor ammoniak- en geuremissies van agrarische Constructies. Saatavissa: http://allserv.rug.ac.be/ pdewisp/gert.html.

SFS-EN 13725:en. 2003. Air quality. Determination of odour concentration by dynamic olfactometry. $71 \mathrm{~s}$. 